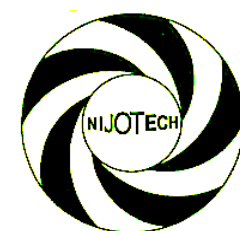

Nigerian Journal of Technology (NIJOTECH)

Vol. 36, No. 4, October 2017, pp. 1208 - 1217

Copyright@ Faculty of Engineering, University of Nigeria, Nsukka,

Print ISSN: 0331-8443, Electronic ISSN: 2467-8821

www.nijotech.com

http://dx.doi.org/10.4314/njt.v36i4.30

\title{
USE OF STANDALONE PHOTOVOLTAIC SYSTEM FOR OFFICE BUILDING: THE CASE STUDY OF NATIONAL CENTRE FOR HYDROPOWER RESEARCH AND DEVELOPMENT, NIGERIA
}

\author{
A. S. Oladeji ${ }^{1,}{ }^{*}$, O. S. Balogun ${ }^{2}$ and S. O. Aliyu ${ }^{3}$ \\ 1, 2NATIONAL CENTRE For Hydropower RESEARCH AND DEVT., UNiv. of ILORIN, ILORIN, KWARA STATE, NIGERIA \\ 3, Dept. of Telecommunication Engineering, Federal Univ. of TeChnology, Minna, Niger State Nigeria \\ E-mail addresses:1akinsun3k@yahoo.co.uk,2olasoulman@yahoo.com,33salihu.aliyu@futminna.edu.ng
}

\begin{abstract}
This paper presents the design of a cost effective energy system for National Centre for Hydropower Research and Development (NACHRED) building to supply its daily energy requirements. The daily hourly load demand of the building was measured with FLUKE 434 Series II Energy Analyzer. The measurement was grouped into two namely: category 1 and category 2. In category 1, the essential electrical load demand excluding air conditioner system was measured for 3 consecutive days while in category 2 the total daily load demand including air conditioner system was also measured for three consecutive days. HOMER pro3.2 was used to size and simulate photovoltaic system required for the two categories. The system in category 1 with the load of an average consumption of $36.34 \mathrm{kWh} / \mathrm{d}$, is considered as a cost effective system for the building, as compared to one in category 2 with the load of an average consumption of $198.1 \mathrm{kWh} / \mathrm{d}$.
\end{abstract}

Keywords: Renewable Energy, Insolation, Electrical Load Demand, Self-Sufficient, Grid

\section{INTRODUCTION}

The reserve of fossil fuel used forelectric power generation worldwide is decreasing rapidly with continuous increase in electrical load demand. As the demands for energy around the world is increasing, the continuous search for renewable energy source that will not damage the environment is also increasing. Harnessing of electric power has brought dramatic changes in the way a society functions, particularly in the developed world, to the extent that without electricity the contemporary society would not be able to exist [1]. Many countries in the World have taken serious initiatives to tap renewable energy resources like solar, hydro, wind etc., which are abundant and environment friendly. Countries interested in clean energy spend huge amount of money both in the research work and in public awareness campaign so as to protect the environment. There is no doubt that high quality research findings will result in low cost of manufacturing the solar system. With expected reduction in component cost and gain in the system performance, attention towards renewable energy alternatives for electric power generation in standalone applications is gaining momentum all over the world [2]. Wind and solar energy technologies are the forerunners amongst various types of renewable sources $[2,3]$.

The most rapidly growing renewable energy sources among various renewable energy resources are PV and wind power. These technologies can be operated as standalone sources, as part of hybrid systems, or as distributed generation connected to a micro grid or a distribution grid [4]. Solar energy is now the third most important renewable energy source after hydro and wind power, in terms of globally installed capacity. The Sun radiates energy of about $3.5 \times 10^{14} \mathrm{~kW}$ into space and only $2 \times 10^{14} \mathrm{~kW}$ reaches the earth [5]. Converting even a part of the solar energy at a very low efficiency can produce more energy than could conceivably be harnessed or utilized for power generation and in many other applications. If $90 \%$ of the solar energy reaching the earth is lost by reflection, refraction and absorption in the outer layers of the atmosphere, the quantity available at the surface will still be about $2 \times 10^{14} \mathrm{~kW}$, which is equivalent to burning of some 17 million tonnes of coal [5]. This stupendous solar energy, which is non-exhaustible and completely pollution free could drive the civilization for many generations to come if properly and economically harnessed. The abundant solar irradiation in Nigeria

\footnotetext{
* Corresponding author, tel: $+\mathbf{2 3 4}-\mathbf{8 0 3 - 8 3 3 - 7 8 8 5}$
} 
has made Photovoltaic system the most promising renewable energy source. Solar system varies in complexity, Stand-Alone (SA) or Off-Grid (OGS) and Grid-Connected (GC) systems. SA or OGS system supply power to a home, water pump or other loads independent of electric utility grid. GC systems work to supplement existing electric power from a utility company. In GC system, when the amount of energy generated by a PV system exceeds the demand loads, excess energy is fed to the utility, thereby turning the energy meter backward. In reverse, the needed power can be drawn from the utility when energy generated from the PV system is insufficient to power the loads demand. In this type of system, the monthly electric utility bill reflects only the net amount of energy consumed from the electric utility.

In Nigeria, the use of solar energy is increasing on a daily bases due to the current epileptic power supply from the utility grid. Besides, the climate condition in Nigeria favors the deployment of solar energy. Hence, the use of this alternate energy source for reliable power supply to offices, residential buildings, remote areas and to reduce high cost of transmission and distribution of electrical energy to rural areas. Therefore, this paper presents a design of a cost effective energy system for National Centre for Hydropower Research and Development (NACHRED) building to supply electric power for the building based on the essential daily energy requirements. For our design stage, we have used the NACHRED building as a case study. The proposed design targets energy efficiency and to make the building practically selfsufficient in energy generation. The system is designed as a standalone solar power system. However, power from the grid is only used to supply the excess demand (air conditioner system demand) so as to ensure the stability and reliability of the system. Sizing of a standalone PV system for supplying the electrical load of the building was done using Hybrid Optimization Model for Electric Renewable (HOMER) software. It is an optimization tool that can be used to design the system configuration for decentralized systems through simulation using different system configurations when required input data is supplied. Homer contains a number of energy component models and evaluates suitable technology options based on cost and availability of resource i.e. it creates a list of feasible system designs and arrange the list in order of cost effectiveness.

\section{BRIEF LITERATURE REVIEW}

Extensive research has been conducted over the year on alternative energy to replace fossil fuel based power generation due to global effect of climate change. Singhal and Singh [6] suggested a renewable energy based alternative to diesel generators for electricity supply using Neil Island in Andaman Island (India) as a case study. In their work they considered power supply for 6 hours in the evening and the study evaluates the feasibility of an alternative, without reporting a real-life diesel-generation replacement case.Dorjiet al. [7] used HOMER energy software to analyze the possible options for electrification of a few of remote settlements in the Kingdom of Bhutan, a small neighboring country of India. A harsh mountainous terrain with many settlements scattered all over the place makes a grid connection impossible in most of the cases. In the work, they considered energy needs of households, available renewable resources and current policies and programs on rural electrification. The study revealed that renewable technologies such as wind-battery or PV-battery can be considered as alternatives to grid connections. The study also shows that the most economical approach differs from site to site.

Chakrabarti and Chakrabarty [8] presented the analysis of solar PV for an island in Sagar Dweep, India. In the work, they considered PV and grid extensions as alternative systems and evaluated the options from economic and environmental perspectives. The work shows that grid extension over long distances is not cost-effective. Sen and Bhattacharyya [9] presentedOffgrid electricity generation with renewable energy technologies in India using HOMER software. In their work, they stressed on the importance of providing reliable and cost-effective electricity to about 1.3 billion people who live without electricity. They emphasize that in many cases extension of the main grid to the area is difficult, thereby recommending off grid electrification as an alternative. They also recommended the use of multiple sources of energy to provide adequate energy to the customers.

Analysis of various system configurations and orientations of grid-connected PV systems was performed by [10]. In [11], the authors presented a paper on grid-connected PV systems for residential houses with energy storage, and studied the relation between storage size and energy flow to the grid in Belgium. In [12], Anagreh et al. presented an investigation of the solar energy potential for seven sites in Jordan and concluded that Jordan has a great solar energy potential which motivates the utilization of stand-alone or grid-connected solar energy systems. In [13] a study of a grid-connected PV system in Hong Kong was presented.

Most of these studies from the literature are hypothetical in nature, they involved interconnection of solar PV and grid supply using net meter for selling excess to the grid or buying deficit from the grid. This practice of interconnection of grid and PV still remains 
impracticable in most of the countries due to unreliability and complexity of the main grid. There is no study that has considered supplying the essential load (light loads) which may be continuous with solar photovoltaic and heavy load which may be discontinuous with the mains grid so as to overcome the challenges of high initial capital cost in harnessing solar energy for electric power generation. This paper tries to explore this knowledge so as to encourage the use of renewable energy (solar energy) especially in the office building and also to encourage the general public to go for solar power plant as a cost effective and economical system even without the incentives.

\section{DESCRIPTION OF THE STUDY AREA}

The NACHRED building is about $2275-\mathrm{m}^{2}$ located on the km18 Ilorin-Ajasepo road, Kwara State, North Central, Nigeria. The building is located on latitude $8^{\circ} 23^{\prime} 50.81^{\prime \prime} \mathrm{N}$ and longitude $4^{\circ} 40^{\prime} 60.38 \mathrm{E}$. The location of the building using Google map is shown in Figure 1. The temperature range is 14.5 to $26.2^{\circ} \mathrm{C}$ in dry season and 17.7 to $23.1^{0} \mathrm{C}$ in rainy season. The area has a good yearly average of daily sums of global horizontal irradiation. The yearly average of daily sums of global horizontal irradiation in Nigeria is shown in Figure 2. The site has a very low wind speed. The study area is characterized by vast plain area which is perfect for Photovoltaic power plants projects. The building is used by the researchers and the management staff of the center all over the year. One of the research group's missions is to study the feasibility of harnessing available renewable energy sources in the surrounding community. This research aims to design and implement a grid-connected PV system that provides the required electrical power to the different laboratories, seminar room, offices, external lighting and library. The electrical loads of the building consists of air-conditions, lamps, fans, computers, photocopier, refrigerators and other loads. The average maximum load demands of the building including air conditioner system is approximately $32 \mathrm{~kW}$ while the average maximum demand without air conditioner system is approximately 5kW. Typical electrical appliances used in NACHRED building is shown in Table I. However, these loads do not work all at one time on the contrary, working for a short time.

\subsection{Solar Irradiation}

The solar irradiance data were obtained from NASA Surface meteorology and Solar Energy [13] (month/day/year) from 01/01/2001 through $30 / 12 / 2005$. It can be seen from Figure 2 above that the average solar radiation in Ilorin is very high (around $5.3 \mathrm{kWh} / \mathrm{m}^{2} / \mathrm{d}$ ), which is suitable for Photovoltaic generation, and the clearness index shows that the study area is a sunny area, which predicts a promising energy production. As shown in Figure 3 that the maximum solar radiation occurs in March with the irradiation of $6.04 \mathrm{kWh} / \mathrm{m}^{2} / \mathrm{d}$ which is a very high value, and the lowest average radiation is in the month of August with $3.76 \mathrm{kWh} / \mathrm{m}^{2} / \mathrm{d}$. It's clear from the site analysis and solar radiation data that the proposed location has a great potential for a PV energy generation project. Scaling was done on this data to consider the long-term average annual resource $\left(5.05 \mathrm{kWh} / \mathrm{m}^{2} / \mathrm{d}\right)$ for the proposed site. HOMER introduces the clearness index from the latitude information of the site under investigation as shown in Figure 3.

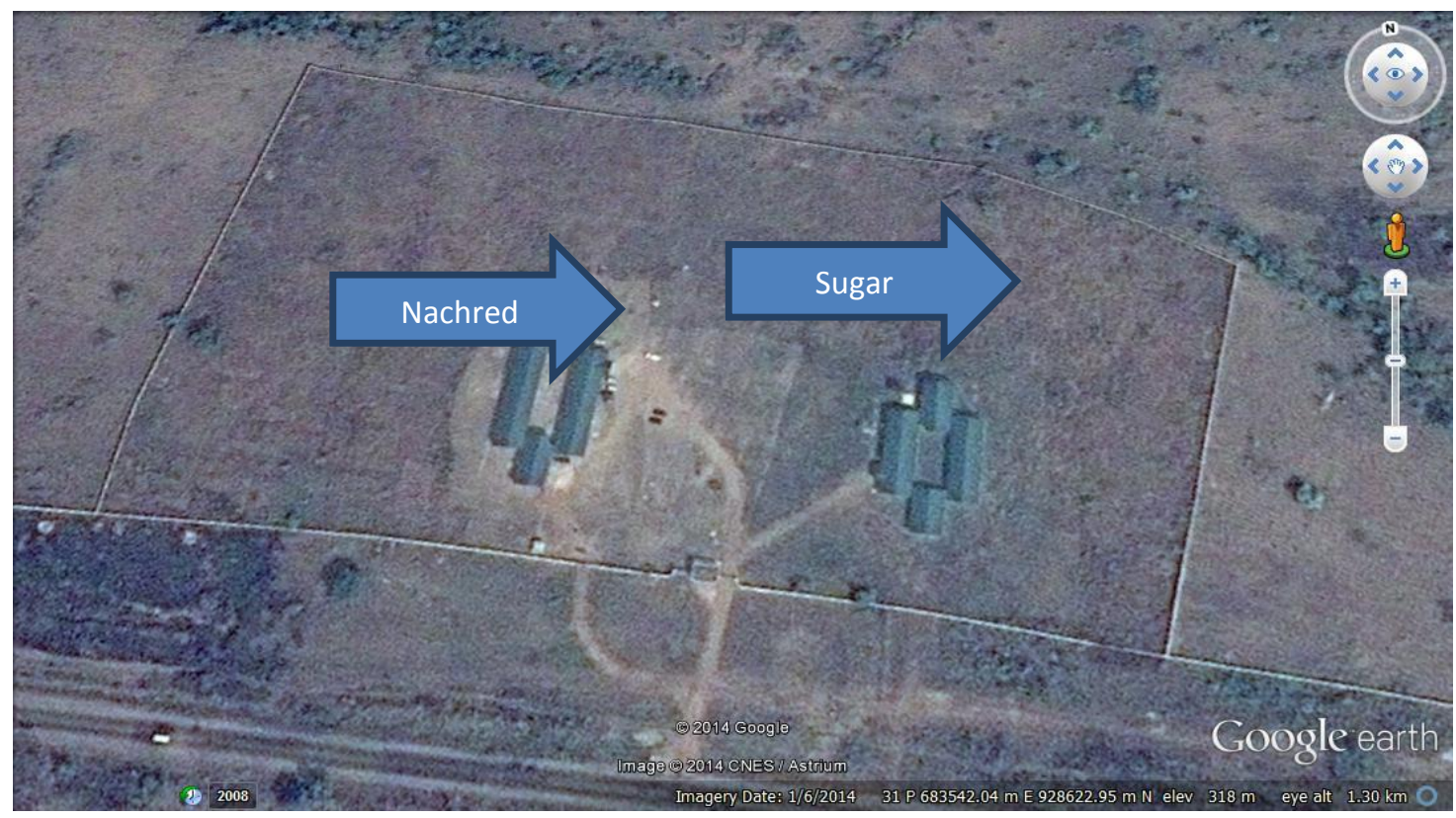

Figure 1: Geographical Location of the Study Area 


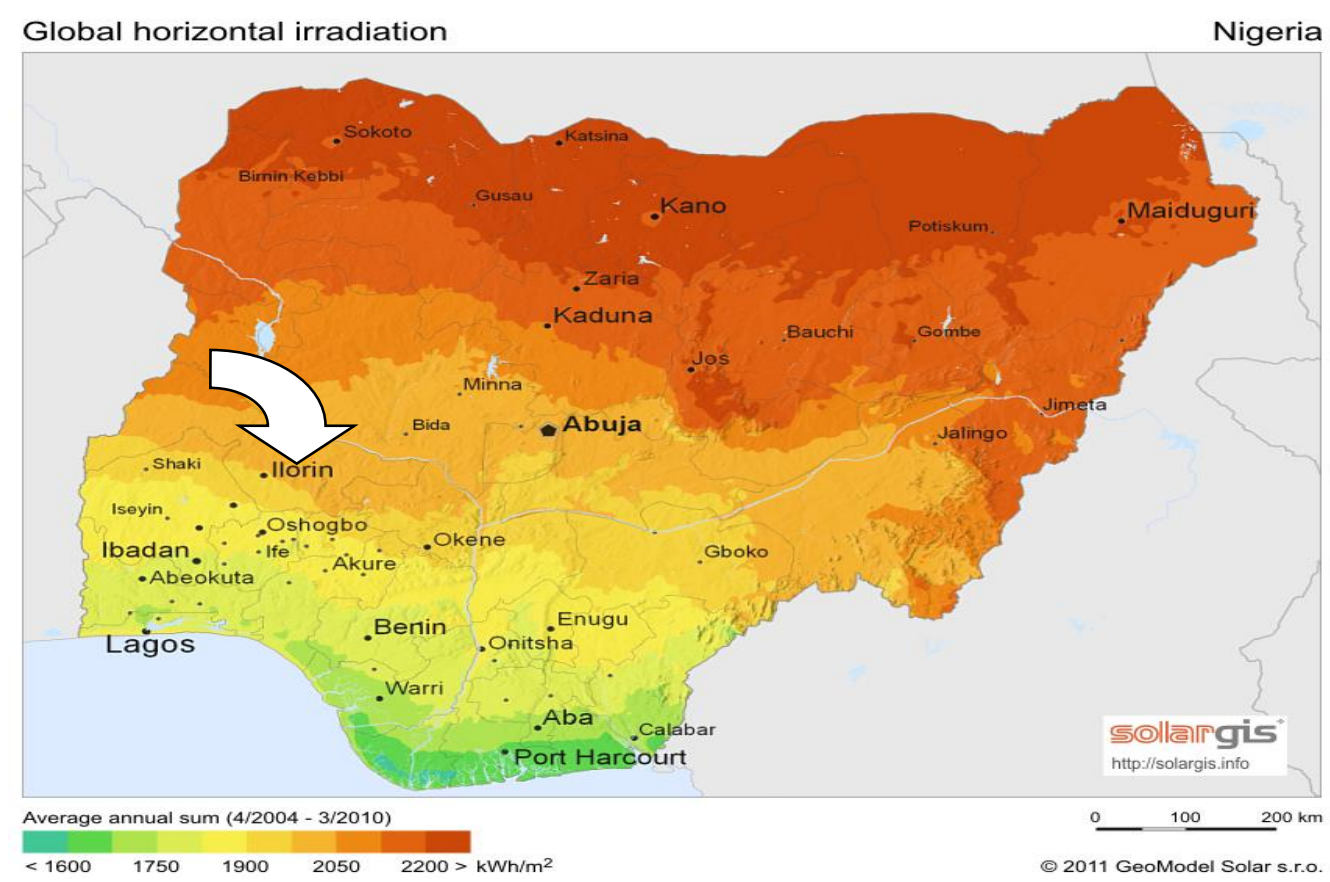

Figure 2: Yearly Average of Daily Sums of Global Horizontal Irradiation in Nigeria

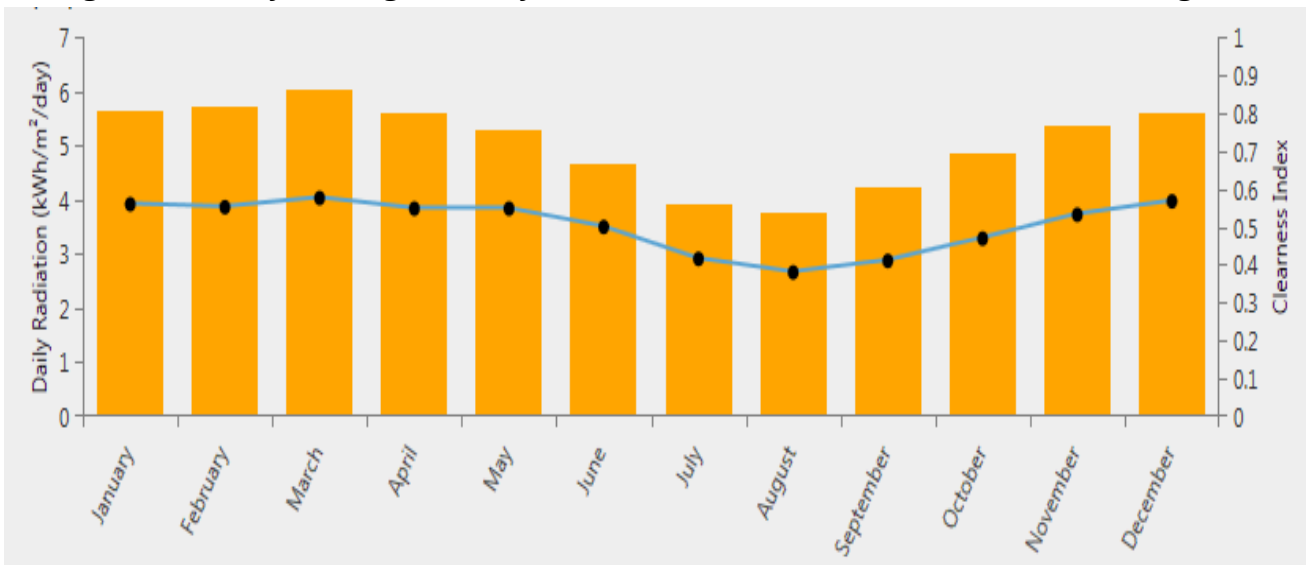

Figure 3: Average Daily Radiation of the Study Area

\section{THE LOAD PROFILE}

Observing/Measuring the load profile of an area is of utmost importance in designing an affordable, a reliable and an efficient stand-alone/grid connected system for an area. The hourly electrical energy demand and the maximum demand (peak load) have great effect on the Cost of Electricity (COE) and the reliability of the system. The hourly load demand of the case study area was measured with Fluke 434 Series II Energy Analyzer. The setup of the measurement is shown in Figure 4. The measurement was grouped into two categories namely: category 1 and category 2 .

In category 1, the essential electrical load demand excluding air conditioner system was measured for 3 consecutive days as shown Figure 5(a)-(c) while in category 2 the total daily load demand including air conditioner system was also measured for three (3) consecutive days as shown in Figure 6(a)-(c). The average hourly load demand for the two categories were determined and plotted as shown in Figure 7 and
8 respectively. HOMER Software was used for optimum sizing of the components required for the stand alone solar system as well as COE. The input technical data used for the simulation is shown in Table 2 .

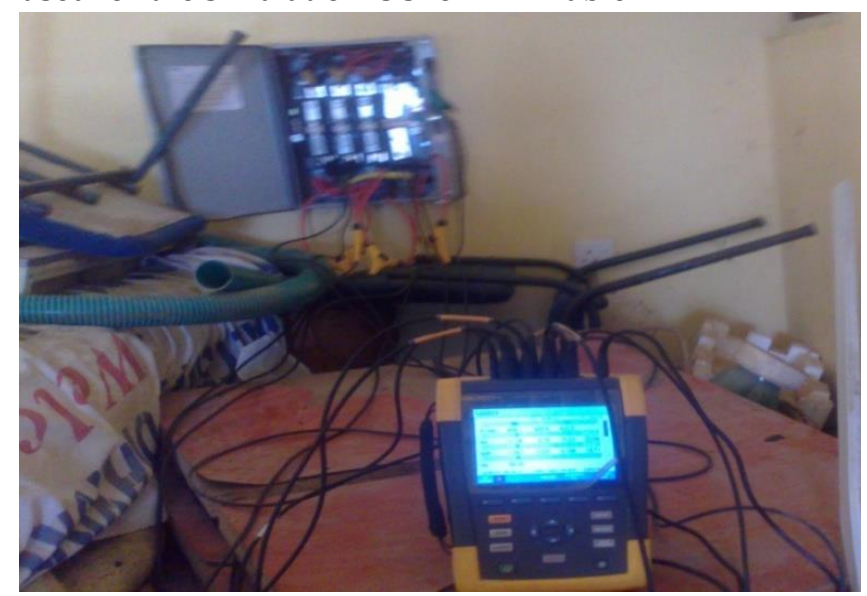

Figure 4: The setup of the Electrical Load Consumption Measurement using FLUKE 434 Series II Energy Analyzer

Vol. 36, No. 4, October 2017 


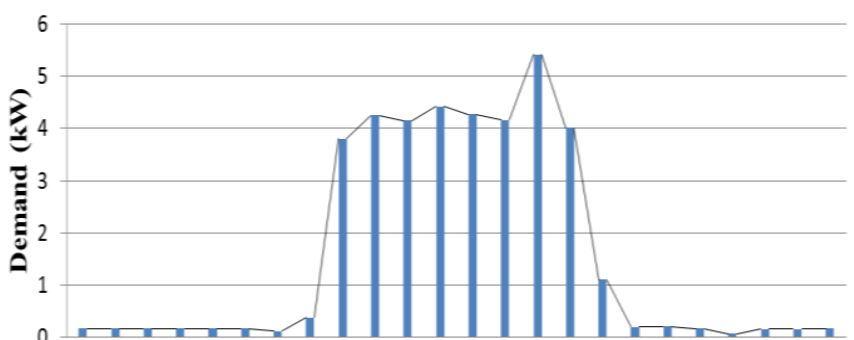

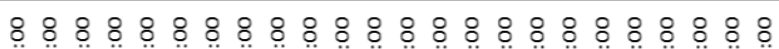
जิ Mे 然 Time Segment (h)

(a): $8 / 6 / 2015$ to $9 / 6 / 2015$

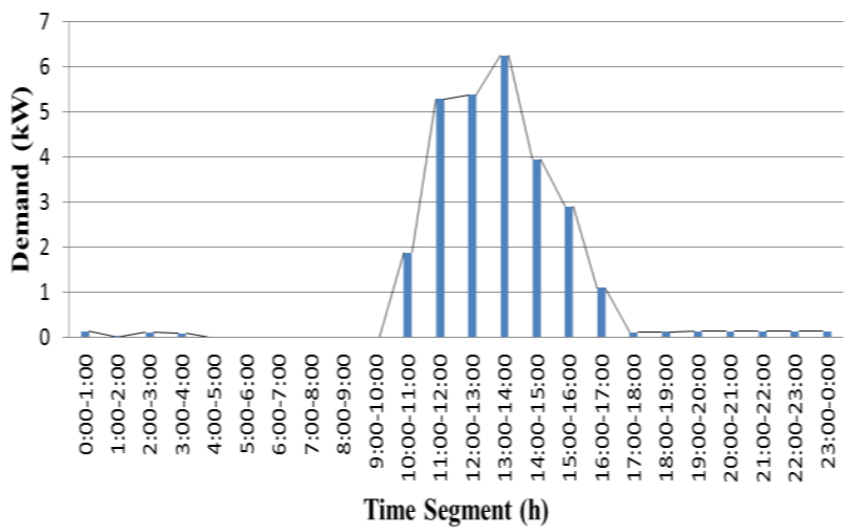

(b): $9 / 6 / 2015$ to $10 / 6 / 2015$

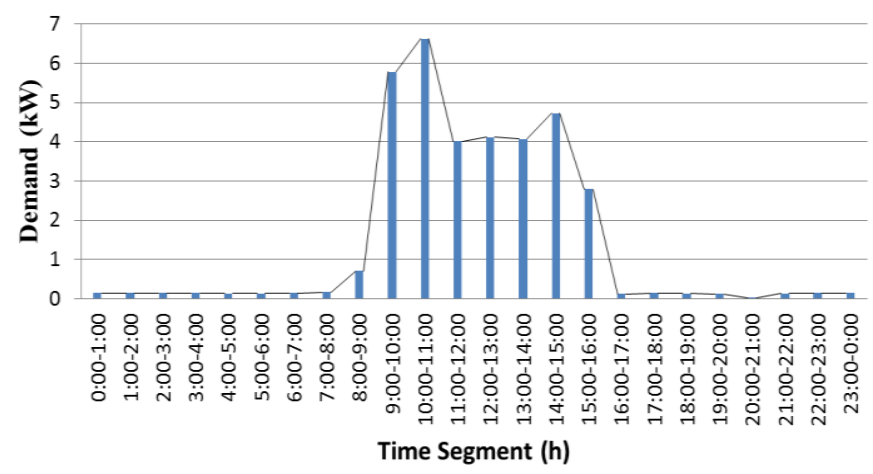

(c): $10 / 6 / 2015$ to $11 / 6 / 2015$

Figure 5 (a)-(c): Daily Load Profile for Three Days

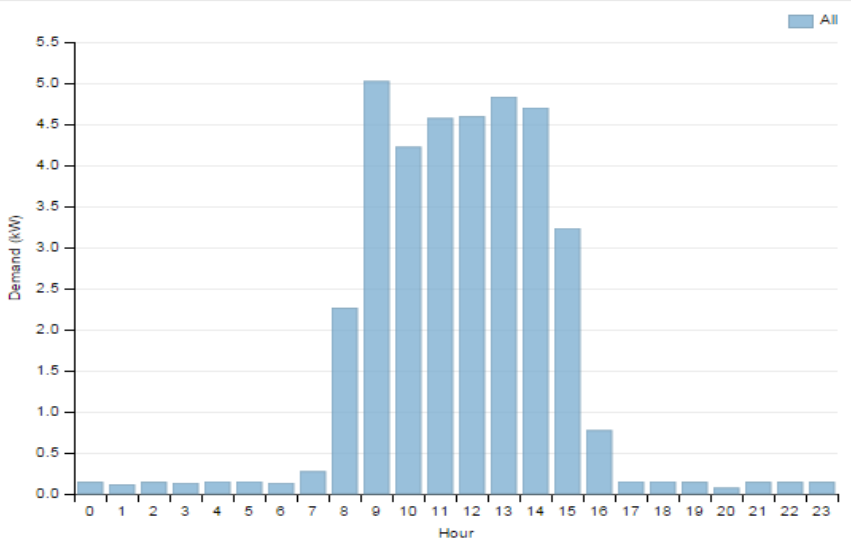

Figure 7: Average Hourly Daily Load Demand of the Building Excluding Air Conditioner System

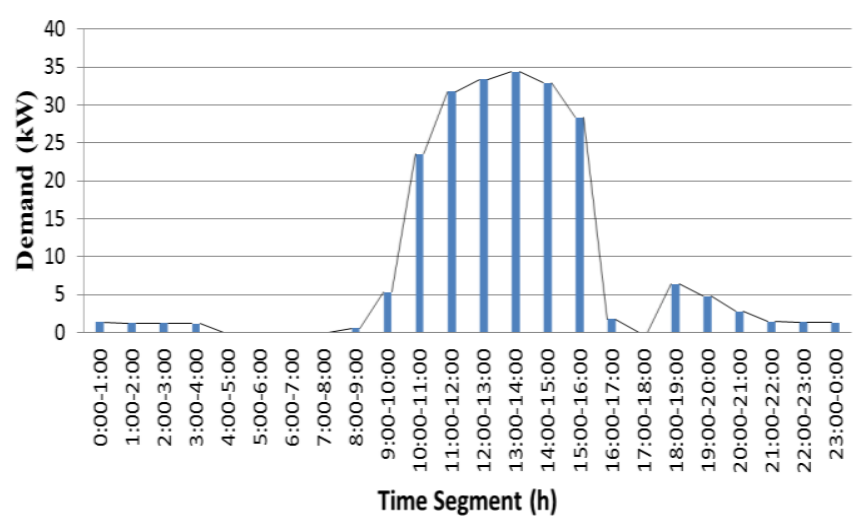

(a): 5/14/2015 to 5/15/2015; 10:02 AM To 9:02 AM

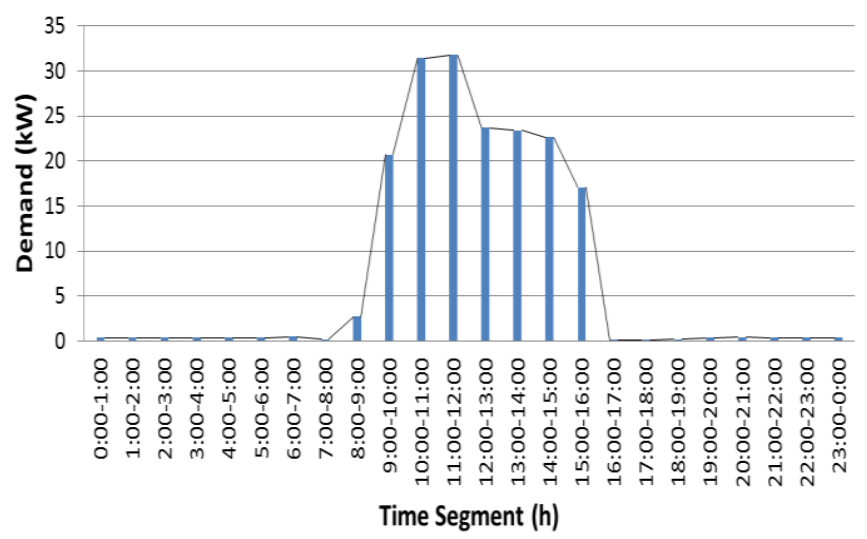

(b): 5/18/2015 to 5/19/2015; 3:31PM To 8:31AM

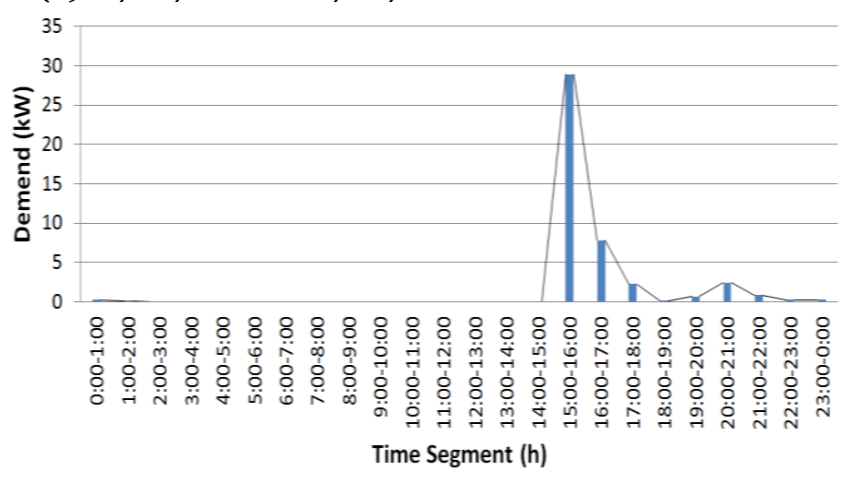

(c): $5 / 20 / 2015$ to $5 / 21 / 2015 ; 12: 43$ PM - 11:43 AM

Figure 6 (a)-(c): Daily load Profile for Three Days

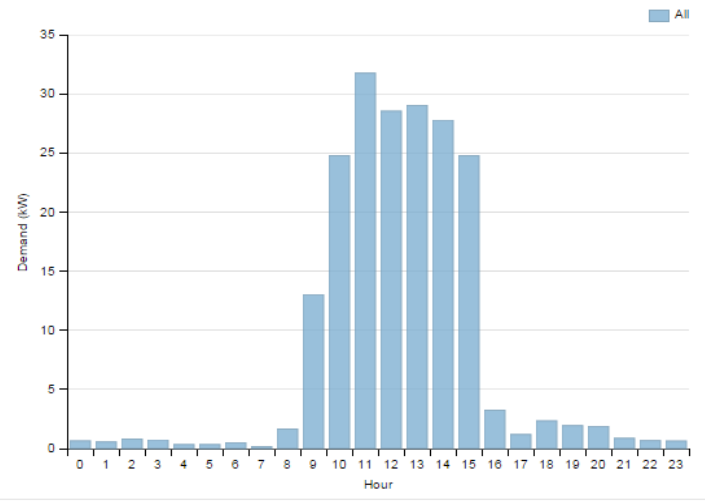

Figure 8: Average Hourly Daily Load Demand of the Total Load Including Air Conditioner System for NACHRED Building

Vol. 36, No. 4, October 2017 
Table 1: Typical Electrical Appliances used in the Study Area

\begin{tabular}{llll}
\hline \multicolumn{1}{c}{ Appliances } & $\begin{array}{c}\text { Power } \\
\text { Rating (W) }\end{array}$ & Quantity & \multicolumn{1}{c}{ Remarks } \\
\hline $\begin{array}{l}\text { Window Air Condition } \\
\text { Split Air Condition }\end{array}$ & 1260 & 12 & \\
Fluorescent Tube & 40 & 13 & \\
Compact Fluorescent & 36 & 66 & $\begin{array}{l}\text { For interior } \\
\text { lighting }\end{array}$ \\
Lamp (CFL) & & 41 & For external/ \\
Ceiling Fan & 80 & 50 & security \\
Laptop & 65 & 16 & \\
Computer Set & 1020 & 18 & \\
Printer & 720 & 4 & \\
Photocopier & 1200 & 1 & \\
Photocopier & 1000 & 1 & \\
Scanner & 240 & 1 & \\
Fridge & 130 & 2 & \\
TV & 75 & 1 & \\
Decoder & 15 & 1 & \\
\hline
\end{tabular}

Table 2: Technical Data and study assumptions of PV, Converter and Batteries

\begin{tabular}{ll}
\hline \multicolumn{1}{c}{ Description } & \multicolumn{1}{c}{ Data } \\
\hline Scaled annual average & $198.100 \mathrm{kWh} / \mathrm{d}$ \\
Scaled peak load & $55.4496 \mathrm{~kW}$ \\
Load factor & 0.1489 \\
PV Panel Price Capital & $\$ 2,200(\mathrm{~N} 671,000)$ \\
Cost/kW & \\
PV Panel Price Replacement & $\$ 2,200(\mathrm{~N} 671,000)$ \\
Cost/kW & $25 \mathrm{years}$ \\
Life Span of PV & $90 \%$ \\
Derating Factor & 8.23 \\
Slope & $20 \%$ \\
Ground Reflectance & Trojan T-105 \\
Types of Battery & $6 \mathrm{~V}$ \\
Nominal Voltage & $225 \mathrm{AH}$ \\
Nominal Capacity & $\$ 100 / \mathrm{Unit}(\mathrm{N} 30,500)$ \\
Capital Cost of Battery & $\$ 100 / \mathrm{Unit}(\mathrm{N} 30,500)$ \\
Battery Replacement Cost & $\$ 10 / \mathrm{Unit}(\mathrm{N} 3,050)$ \\
Battery Maintenance Cost & $100 \%$ \\
Initial State of Charge & $30 \%$ \\
Minimum State of Charge & $845 \mathrm{kWh}$ \\
Lifetime Throughput & $\$ 1000 / \mathrm{kW}(\mathrm{N} 305$, \\
Capital Cost of Inverter & $000 / \mathrm{kW})$ \\
& $\$ 1000 / \mathrm{kW}(\mathrm{N} 305$, \\
Replacement Cost of Inverter & $000 / \mathrm{kW})$ \\
& $\$ 100 / \mathrm{kW}(\mathrm{N} 30$, \\
Maintenance Cost of Inverter & $500 / \mathrm{kW})$ \\
Life Span of Inverter & $30 \mathrm{years}$ \\
Annual real Interest Rate & $6 \%$ \\
Project Life Time & $25 \mathrm{years}$ \\
Capacity shortage penalty & $\$ 0 \mathrm{kWh}$ \\
System fixed capital cost & 0 \\
System fixed O\&M cost & 0 \\
Maximum annual capacity & 0 \\
shortage & 0 \\
Minimum renewable fraction & \\
\hline & \\
\hline
\end{tabular}

\section{SYSTEM CONFIGURATION}

The PV system was modeled using HOMER pro 3.2 (HOMER Professional Micro-grid Analysis Tool). Figures 9 and 10 show the system configuration used in this paper for category 1 and 2 respectively. The system in category 1 is composed of $14 \mathrm{~kW}$ of PV, $10 \mathrm{~kW}$ of converter and 16 strings of Trojan T-105, 6V, 225AH ( 8 batteries per String $=48 \mathrm{~V}$ ) with the load of an average consumption of $36.34 \mathrm{kWh} / \mathrm{d}$ and peak demand of $8.59 \mathrm{~kW}$, while system in category 2 is composed of $115 \mathrm{~kW}$ of PV, $58 \mathrm{~kW}$ of converter and 20 strings of Trojan T-105, 6V, 225AH (20 batteries per String = $120 \mathrm{~V}$ ) with the load of an average consumption of $198.1 \mathrm{kWh} / \mathrm{d}$ and peak demand of $55.45 \mathrm{~kW}$.

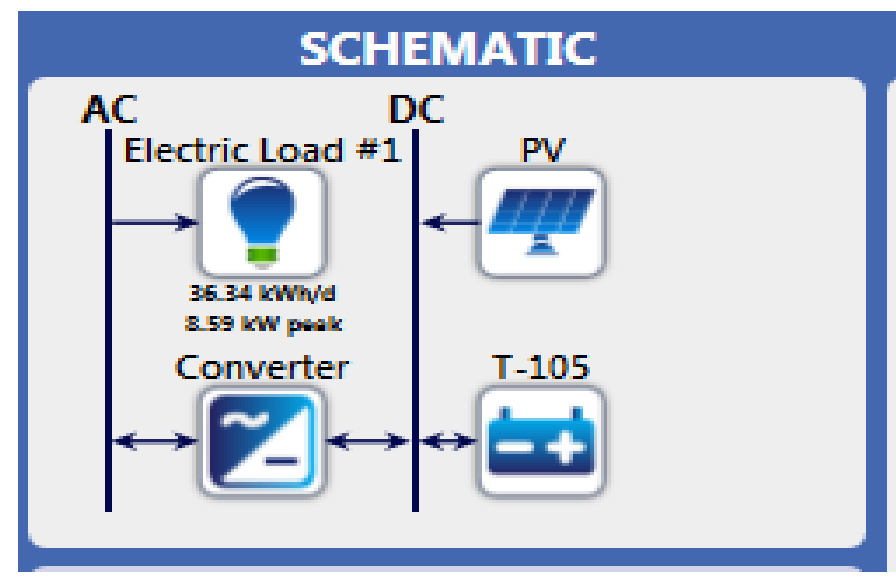

Figure 9: PV System Configurations for Category 1

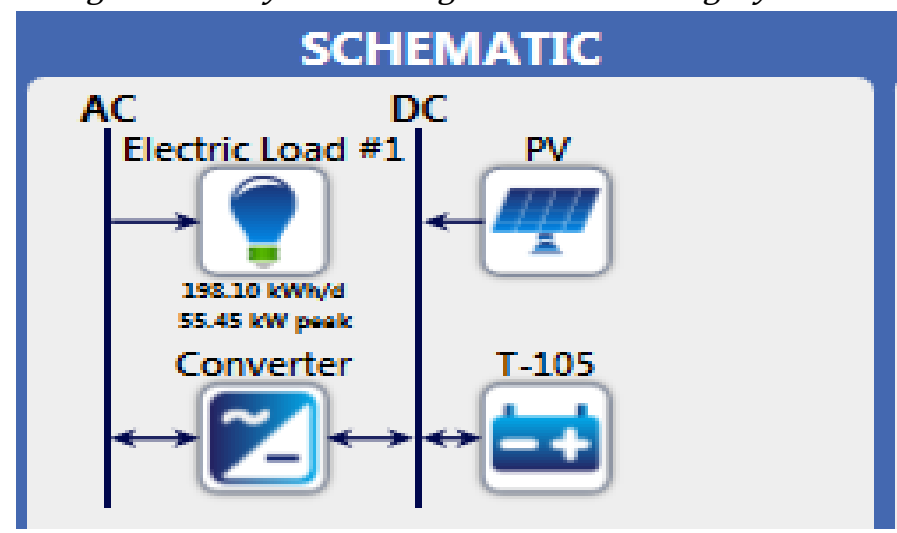

Figure 10: PV System Configurations for Category 2

\section{RESULTS AND DISCUSSIONS}

After running the input data through HOMER pro 3.2 software, Sensitivity cases are listed in the top table, and simulation runs are listed in the bottom results as shown in Figures 11 and 12 for categories 1 and 2 respectively. The system architecture for the optimal result for the 2 categories is tabulated in Table 3. Total and leveled Cost of Energy of the optimal configuration is $\$ 92,450(\mathrm{~N} 28,197,250)$ and $\$ 0.539 / \mathrm{kWh}$ (N164/kWh) for category 1 and $\$ 505,920$ (N154, 305, $600)$ and $\$ 0.542 / \mathrm{kWh}(\mathrm{N} 165 / \mathrm{kWh})$ for category 2 
respectively as shown in Table 4 (using official exchange rate of $1 \$$ to $\mathrm{N} 305)$. It can be seen in Table 4 that in order to meet up with the essential load demand of building excluding air conditioner system using stand-alone solar system the cost of the system is far cheaper and encouraging as compared to supplying the essential load plus air conditioner system.The summary of the system cost by component type for categories 1 and 2 is shown in Figures 13 and 14. In Figure13, the highest part of the system cost is due to the batteries, on the other hand the converters and the PV panels have a relatively low capital cost but their maintenance and operation costs contribute to the overall cost. Also, in Figure 14, the highest part of the system cost is due to the PV panels but has no maintenance and operation costs, on the other hand the converters and the batteries has a relatively low capital cost but it contribute to the total cost through maintenance and operation cost. The cash flow by cost type from 0-25 years (life time of the project) for categories 1 and 2 is shown in Figures 15 and 16 with capital cost of $\$ 53,000$ (N16, 165, 000) which is $57: 3 \%$ of the total cost at year 0 for category 1 and capital cost of $\$ 351,000$ (N197, 055, 000) which is $69.4 \%$ of the total cost at year 0 for category 2 . It should be noted here that since the major disadvantage of utilizing solar photovoltaic system for power generation has always being due to the high initial capital cost. As seen in Figure 15, the initial capital from the cash flow needed to kick start the projectis far cheaper and encouraging as compared to that in Figure 16.
Moreover,it can be seen from Table 5that with the above system configuration for category 1, un-met load is $0 \mathrm{kWh} / \mathrm{yr}$ and excess energy of about $8843 \mathrm{kWh} / \mathrm{yr}$ is generated. It should be noted here, that this excess energy produced caneither go to the dump load or used by miscellaneous load. Also, it can be seen from Table 6for category 2 that, un-met load is $53 \mathrm{kWh} / \mathrm{yr}$ and excess energy of about $112648 \mathrm{kWh} /$ yris generated. This excess energy produced goes unused due to lack of demand.

In the block diagram shown in Figure17, priority is given to the essential load demand of the building excluding air conditioner system. The PV system is designed to meet up with the essential load demand and the power from the grid to supply energy demand of the air conditioner system when required. The scope is to practice energy efficiency and to make the building practically self-sufficient in energy generation. This will reduce the burden of high initial cost of renewable energy. It should be noted here that during rainy season, the demand for air conditioner systemand fan is always low. With the help of this cost effective design, the building will enjoy reliable supply of electricity required to meet up with its daily activities as power outage from the main grid will not affect activities in the building, since electricity from the grid is only needed to power the air conditioner system only when needed as shown in Figure 17. The PV/Grid for the building has been designed in such a way that once there is no mains supply from the grid all the air conditioner system would not work so as to avoid the abuse of system by the staff.

\begin{tabular}{|c|c|c|c|c|c|c|c|c|c|c|c|c|c|}
\hline \multirow{2}{*}{$\begin{array}{c}\text { Sensitivity } \\
\text { Solar } \\
\text { Scaled Average } \\
\text { (kWh } / \mathrm{m}^{2} / \text { day) }\end{array}$} & \multicolumn{8}{|c|}{ Architecture } & \multicolumn{4}{|c|}{ Cost } & \multirow{2}{*}{$\begin{array}{c}\text { System } \\
\begin{array}{c}\text { Ren Frac } \checkmark \\
(\%)\end{array}\end{array}$} \\
\hline & $\triangle$ & $\%$ & $t$ & z & $\underset{(\mathrm{kW})}{\mathrm{PV}} \nabla$ & T-105 マ & $\begin{array}{c}\text { Converter } \nabla \\
(\mathrm{kW})\end{array}$ & Dispatch $\checkmark$ & $\begin{array}{c}\mathrm{COE} \nabla \\
(\$)\end{array}$ & $\begin{array}{l}\mathrm{NPC} \\
(\$)\end{array}$ & $\begin{array}{c}\text { Operating cost } \checkmark \\
(\$)\end{array}$ & $\begin{array}{c}\text { Initial capital } \checkmark \\
(\$)\end{array}$ & \\
\hline 5.05 & & 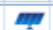 & -4 & z & 14.0 & 128 & 10 & $\mathrm{CC}$ & $\$ 0.539$ & $\$ 92,450$ & $\$ 3,005$ & $\$ 53,600$ & 100 \\
\hline
\end{tabular}

\begin{tabular}{|c|c|c|c|c|c|c|c|c|c|c|c|c|c|}
\hline \multicolumn{4}{|c|}{ Export... } & \multicolumn{10}{|c|}{ Optimization Cases: Left Double Click on simulation to examine details. } \\
\hline \multicolumn{8}{|c|}{ Architecture } & \multicolumn{4}{|c|}{ Cost } & \multirow{2}{*}{$\begin{array}{c}\text { System } \\
\text { Ren Frac } \checkmark \\
(\%)\end{array}$} & \\
\hline$\triangle$ & $m$ & $t$ & z & $\underset{(\mathrm{kW})}{\mathrm{PV}} \vee$ & T-105 マ & $\begin{array}{c}\text { Converter } \nabla \\
(\mathrm{kW})\end{array}$ & Dispatch $\checkmark$ & $\begin{array}{c}C O E \\
(\$)\end{array}$ & $\begin{array}{c}\text { NPC } \\
(\$)\end{array}$ & $\begin{array}{c}\text { Operating cost } \checkmark \\
(\$)\end{array}$ & $\begin{array}{c}\text { Initial capital } \checkmark \\
(\$)\end{array}$ & & \\
\hline & $m$ & tet & z & 14.0 & 128 & 10 & $\mathrm{CC}$ & $\$ 0.539$ & $\$ 92,450$ & $\$ 3,005$ & $\$ 53,600$ & 100 & \\
\hline & Pr & tet & z & 15.0 & 128 & 10 & $\mathrm{CC}$ & $\$ 0.552$ & $\$ 94,650$ & $\$ 3,005$ & $\$ 55,800$ & 100 & \\
\hline & $m$ & tet & 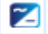 & 15.0 & 128 & 10 & $\mathrm{CC}$ & $\$ 0.552$ & $\$ 94,650$ & $\$ 3,005$ & $\$ 55,800$ & 100 & \\
\hline & $m$ & $t$ & z & 25.0 & 64 & 10 & $\mathrm{CC}$ & $\$ 0.567$ & $\$ 97,089$ & $\$ 1,987$ & $\$ 71,400$ & 100 & \\
\hline & 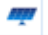 & tet & z & 17.0 & 128 & 10 & $\mathrm{CC}$ & $\$ 0.578$ & $\$ 99,050$ & $\$ 3,005$ & $\$ 60,200$ & 100 & \\
\hline & 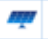 & $t$ & z & 26.0 & 64 & 10 & $\mathrm{CC}$ & $\$ 0.579$ & $\$ 99,289$ & $\$ 1,987$ & $\$ 73,600$ & 100 & \\
\hline & 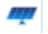 & $t$ & 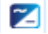 & 18.0 & 128 & 10 & $\mathrm{CC}$ & $\$ 0.590$ & $\$ 101,250$ & $\$ 3,005$ & $\$ 62,400$ & 100 & \\
\hline
\end{tabular}

Figure 11: Optimal Result from HOMER pro 3.2 for category 1 
Use Of Standalone Photovoltaic System for Office Building: the Case Study of National Centre for ... A. S. Oladeji, et al

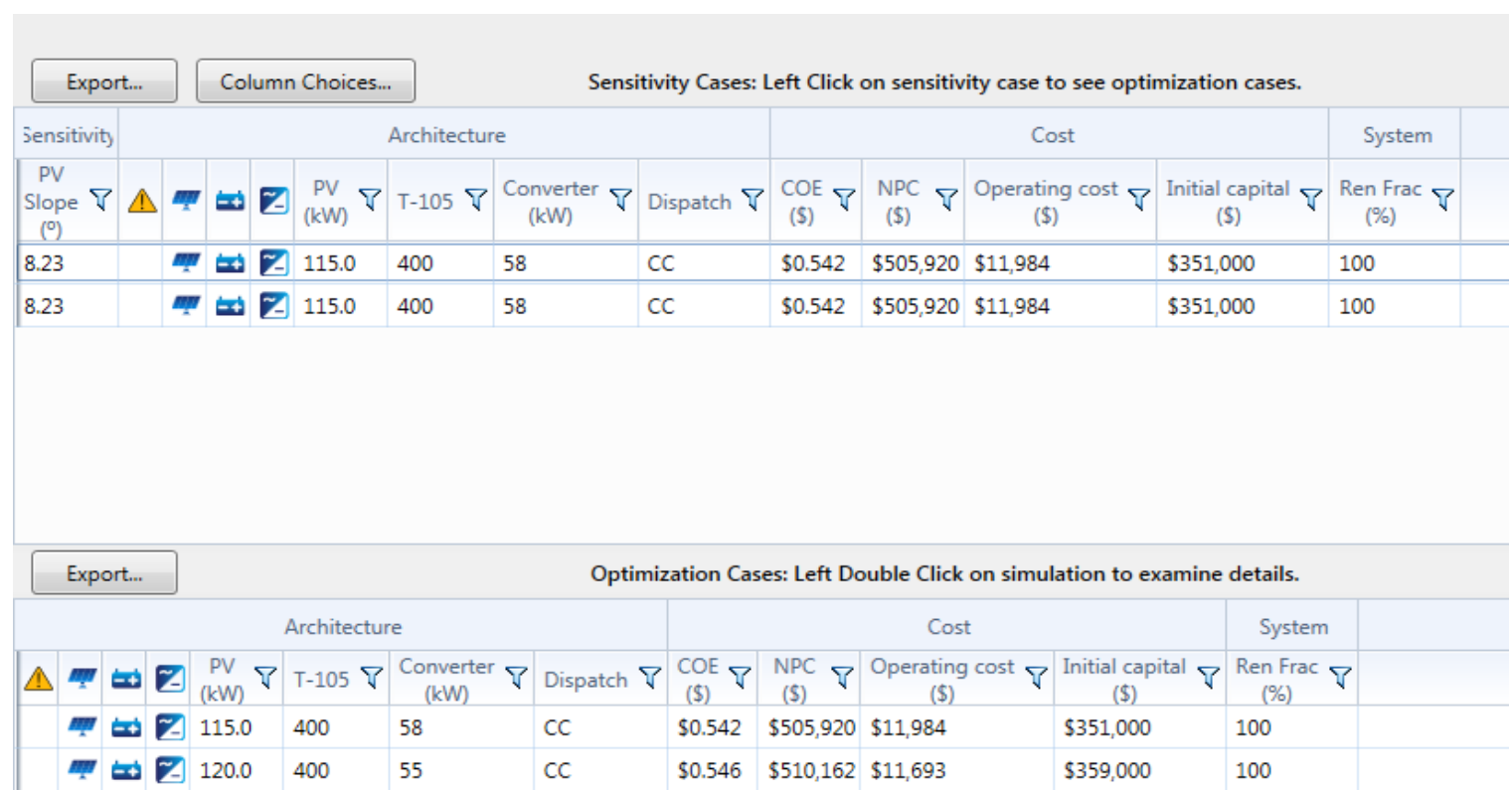

Figure 12: Optimal Result from HOMER pro 3.2 for category 2

Table 3: The System Architecture

\begin{tabular}{lllll}
\hline & & Category 1 & Category 2 & Remarks \\
\hline PV & Generic flat plate PV & $14 \mathrm{~kW}$ & $115 \mathrm{~kW}$ & \\
Battery & Trojan T-105 & 16 strings & 20 strings & $* 8$ batteries per String = 48VDC for Category 1 \\
& & & & $* 20$ batteries per String = 120VDC for Category 2 \\
Converter & System Converter & $10 \mathrm{~kW}$ & $58 \mathrm{~kW}$ & \\
\hline
\end{tabular}

Table 4: Total and Cost of Energy for Category 1 and 2

\begin{tabular}{lll}
\hline & Category 1 & Category 2 \\
\hline Total net present cost & $92450 \$(\mathrm{~N} 28,197,250)$ & $505920 \$(\mathrm{~N} 154,305,600)$ \\
Levelized cost of energy & $0.539 \$ / \mathrm{kWh}(\mathrm{I64} / \mathrm{kWh})$ & $0.542 \$ / \mathrm{kWh}(\mathrm{N} 165 / \mathrm{kWh})$ \\
\hline
\end{tabular}

Table 5: Electrical Simulation Data for Category 1

\begin{tabular}{lll}
\hline Quantity & Value & Units \\
\hline Excess electricity & 8843 & $\mathrm{kWh} / \mathrm{yr}$ \\
Unmet load & 0 & $\mathrm{kWh} / \mathrm{yr}$ \\
Capacity shortage & 0 & $\mathrm{kWh} / \mathrm{yr}$ \\
Renewable fraction & 1 & \\
\hline
\end{tabular}

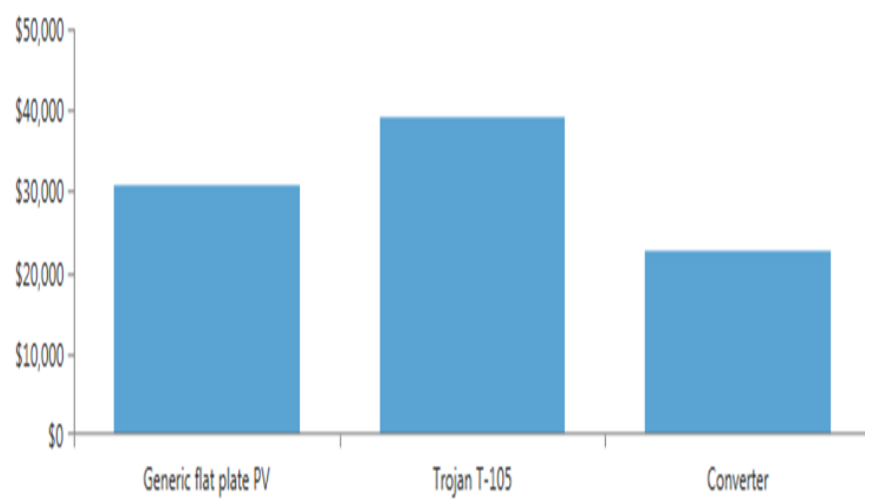

Figure 13: The Summary of the System Cost by Component Type for Category 1
Table 6: Electrical Simulation Data for Category 2

\begin{tabular}{lll}
\hline Quantity & Value & Units \\
\hline Excess electricity & 112648 & $\mathrm{kWh} / \mathrm{yr}$ \\
Unmet load & 53 & $\mathrm{kWh} / \mathrm{yr}$ \\
Capacity shortage & 68 & $\mathrm{kWh} / \mathrm{yr}$ \\
Renewable fraction & 1 & \\
\hline
\end{tabular}

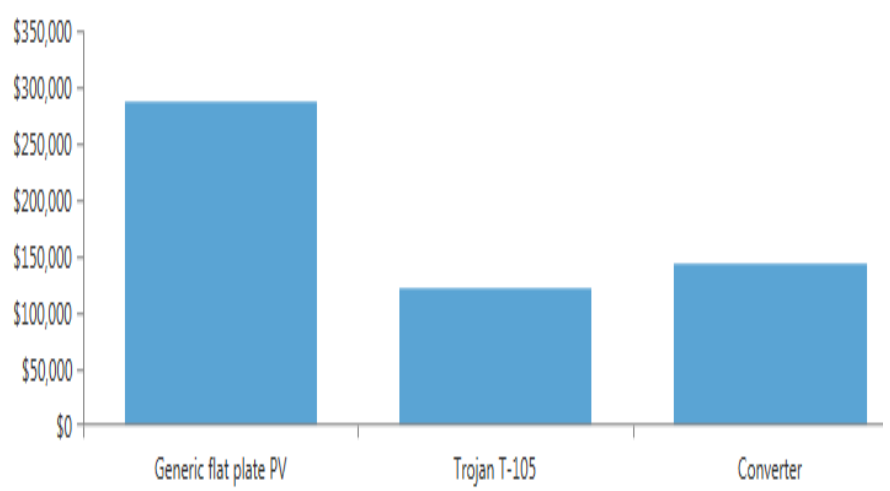

Figure 14: The Summary of the System Cost by Component Type for Category 2

Vol. 36, No. 4, October 2017 


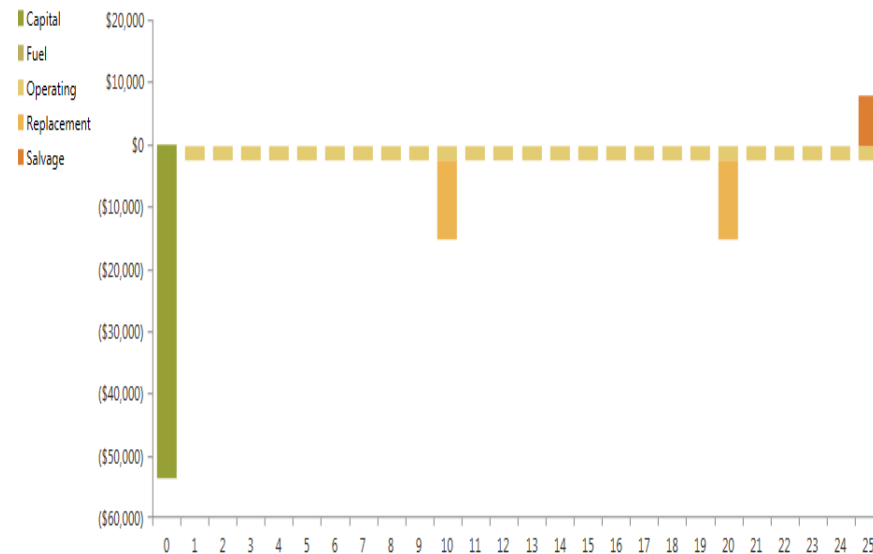

Figure 15: The Cash Flow by Cost Type from 0-25 Years (Life time of the Project) for Category

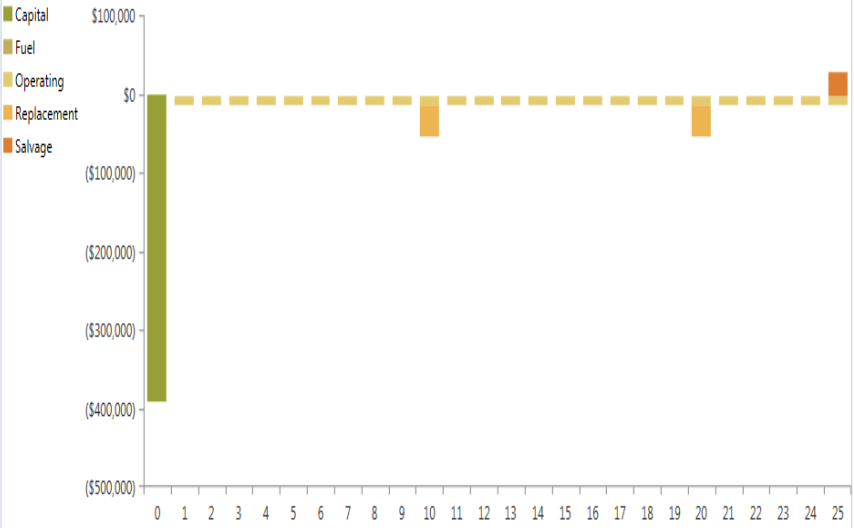

Figure 16: The Cash Flow by Cost Type from 0-25 Years (Life time of the Project) for Category 2

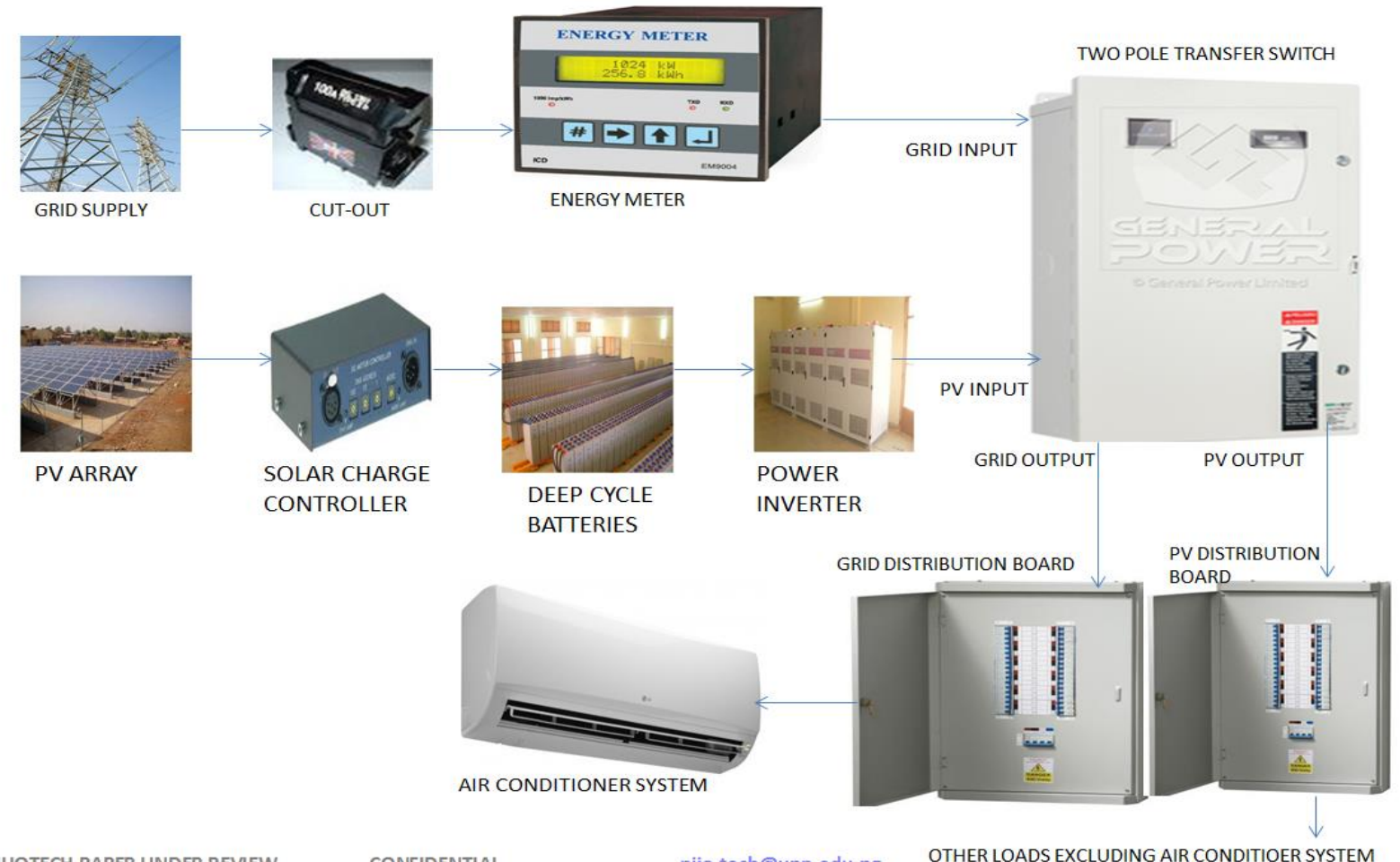

Figure 17: Block Diagram of the Proposed PV-Grid Connection for the Building

\section{CONCLUSION}

This paper proposed a cost effective energy system for NACHRED building using solar PV to meet the essential electrical load demand of the building and power from the grid to supply the excess demand (including air conditioner system demand). The electrical load demand of the building was measured using Fluke 434 Series II Energy Analyzer. The measurement was grouped into two categories namely: category 1 and category 2 . In category 1 , the essential electrical load demand excluding air conditioner system was measured for 3 consecutive days while in category 2 the total daily load demand including air conditioner system was also measured for three (3) consecutive days. The average hourly load demand for the two categories were determined and plotted. HOMER pro3.2 was used to size and simulate photovoltaic system required for the two categories. In category 1 which is considered as a cost effective system for the building, the system architecture is composed of $14 \mathrm{~kW}$ of PV, $10 \mathrm{~kW}$ of converter and 16 strings of Trojan T$105,6 \mathrm{~V}, 225 \mathrm{AH}$ ( 8 batteries per String $=48 \mathrm{~V}$ ) with the load of an average consumption of $36.34 \mathrm{kWh} / \mathrm{d}$ and peak demand of $8.59 \mathrm{~kW}$, the total cost of the system is $\$ 92,450 \$(\mathrm{~N} 28,197,250)$ and the cost of energy is $\$ 0.539 / \mathrm{kWh}(\mathrm{N} 64 / \mathrm{kWh})$ which is moderate as compared to the one in category 2.Also, in category 2 which was designed as a stand-alone photovoltaic system, the system architecture is composed of $115 \mathrm{~kW}$ of PV, 20 strings of Trojan T-105, 6V, 225Ah (20 
batteries per String $=120 \mathrm{~V}$ ) and $58 \mathrm{~kW}$ converter with the load of an average consumption of $198.1 \mathrm{kWh} / \mathrm{d}$ and peak demand of $55.45 \mathrm{~kW}$, the total cost of the system is $\$ 505,920(\mathrm{~N} 154,305,600)$ and the cost of energy is $\$ 0.542 / \mathrm{kWh}(\mathrm{N} 165 / \mathrm{kWh})$ which is still a high cost as compare to system architecture in category 1 . The block diagram of recommended cost effective system was also provided. Power from the grid will only be used to supply the excess demand (air conditioner system demand) so as to ensure the stability and reliability of the system. With the on-going high quality research, the cost of manufacturing the solar system is reducing daily. With expected reduction in the component cost and gain in the system performance, attention towards renewable energy alternatives for electric power generation in stand-alone applications will continue to gain momentum all globally.

\section{RECOMMENDATIONS}

1. Due to the global effect of climate change and greenhouse gases, gradual depletion of fuel supply, continuous increase in daily energy consumption, the belief that world's fossil fuel which contribute to largest percentage of power being presently generated will be exhausted one day, plus the fact that reserve of the fossil fuel cannot sustain the sustainable development of the future, hence, alternative energy sources that will not pollute the environment like solar, wind, small hydropower etc. must be properly and economically harnessed to meet up with present and future energy needs.

2. A strong political will to formulate policy to mandate government offices to use renewable energy sources like solar and wind to power at least basic load demand

3. Government should provide incentives to encourage the use of solar energy to power basic electrical appliances for residential, commercial and industrial buildings.

4. Government and the energy utility companies should create frequent awareness in the area of energy efficiency (campaigning for the use of energy savers appliances) and sustainable use of electrical energy so as to reduce the high initial capital cost of installation of solar system and maximum daily load demand.

\section{ACKNOWLEDGEMENT}

This research work was supported by the National Centre for Hydropower Research and Development, University of Ilorin, Nigeria.

\section{REFERENCES}

[1] Zbigniew, C., Subhes C. B. Analysis of off-grid electricity system at Isle of Eigg (Scotland): Lessons for developing countries. Renewable Energy 81 pp. 578-588. 2015.

[2] Khan, M. J., Iqbal M. T. Pre-feasibility study of stand-alone hybrid energy systems for applications in Newfoundland. Renewable Energy 30 pp. 835-854, 2005.

[3] Mann, M., K. Economics of renewable hydrogenit's about more than production. Renewable Hydrogen Energy Forum, Washington, DC; April 10-11, 2003.

[4] Ismail M., Moghavvemi M., Mahlia T., Muttaqi K., \&Moghavvemi S., Effective utilization of excess energy in standalone hybrid renewable energy systems for improving comfort ability and reducing cost of energy: A review and analysis. Renewable and Sustainable Energy Reviews, vol. 42, pp. 726-734.

[5] Gupta, J. B. 'A Course in Power Systems' Sanjeev, Kumar Kataria and Sons, NaiSarak, Delhi 2000.

[6] Singhal S.K., Singh R.P. Rural electrification of a remote island by renewable energy sources. Renew Energy; 32(15):2491-501. 2007.

[7] Dorji T., Urmee T., Jennings P. Options for off-grid electrification in the Kingdom of Bhutan. Renew Energy; 45:51-8. 2012.

[8] Chakrabarti S., Chakrabarti S. Rural electrification programme with solar energy in remote region-a case study in an island. Energy Policy, 30(1): 3342. 2002.

[9] Sen R., Bhattacharyya S. Off-grid electricity generation with renewable energy technologies in India: an application of HOMER. Renew Energy 62:389. 2014;

[10] Udea, Y.Kurokawa, K., Kitamura, K., Yokota, M., Akanuma, K., \& Sugihara, H. Performance analysis of various system configurations on gridconnected residential PV systems. Solar Energy Materials \& Solar Cells, pp. 945-949. 2009.

[11] Mulder, G., De-Ridder, F., and Six, D. Electricity storage for grid connected household dwellings with PV panels. Solar Energy, ,84, pp.-1293. 2010.

[12] Anagreh, Y., Bataineh, A., and Al-Odat, M. Solar energy potential in Jordan. ICEGES, 2009,

[13] NASA Surface meteorological and Solar Energy: Daily Average Data. Available on line at https: / /www.google.com.ng/maps. Accessed on line on5 ${ }^{\text {th }}$ May, 2015. 